\title{
Acute dissociation after 1 night of sleep loss
}

Citation for published version (APA):

Giesbrecht, T. M., Smeets, T., Merckelbach, H. L. G. J., Jelicic, M., \& Leppink, J. (2007). Acute dissociation after 1 night of sleep loss. Journal of Abnormal Psychology, 116(3), 599-606. https://doi.org/10.1037/0021-843X.116.3.599

Document status and date:

Published: 01/01/2007

DOI:

10.1037/0021-843X.116.3.599

Document Version:

Publisher's PDF, also known as Version of record

\section{Please check the document version of this publication:}

- A submitted manuscript is the version of the article upon submission and before peer-review. There can be important differences between the submitted version and the official published version of record.

People interested in the research are advised to contact the author for the final version of the publication, or visit the DOI to the publisher's website.

- The final author version and the galley proof are versions of the publication after peer review.

- The final published version features the final layout of the paper including the volume, issue and page numbers.

Link to publication

\footnotetext{
General rights rights.

- You may freely distribute the URL identifying the publication in the public portal. please follow below link for the End User Agreement:

www.umlib.nl/taverne-license

Take down policy

If you believe that this document breaches copyright please contact us at:

repository@maastrichtuniversity.nl

providing details and we will investigate your claim.
}

Copyright and moral rights for the publications made accessible in the public portal are retained by the authors and/or other copyright owners and it is a condition of accessing publications that users recognise and abide by the legal requirements associated with these

- Users may download and print one copy of any publication from the public portal for the purpose of private study or research.

- You may not further distribute the material or use it for any profit-making activity or commercial gain

If the publication is distributed under the terms of Article $25 \mathrm{fa}$ of the Dutch Copyright Act, indicated by the "Taverne" license above, 


\title{
Acute Dissociation After 1 Night of Sleep Loss
}

\author{
Timo Giesbrecht \\ Maastricht University and Mount Sinai School of Medicine
}

\author{
Tom Smeets, Jimmie Leppink, Marko Jelicic, and \\ Harald Merckelbach \\ Maastricht University
}

\begin{abstract}
Recent research has shown that dissociative symptoms are related to self-reports of deviant sleep experiences. The present study is the 1st to explore whether sleep loss can fuel dissociative symptoms. Twenty-five healthy volunteers were deprived of sleep for 1 night. Sleepiness and dissociative symptoms were assessed every $6 \mathrm{hr}$. The authors measured both spontaneous dissociative symptoms and dissociative symptoms induced by dot-staring during sensory deprivation. Sleepiness as well as spontaneous and induced dissociative symptoms were stable throughout the day but increased during the night. These findings provide further evidence for a robust relationship between disruptions in sleep patterns and dissociative symptoms.
\end{abstract}

Keywords: dissociation, sleep deprivation, sleepiness, dissociative disorders

Sleep deprivation is prevalent and has a considerable health, social, and economical impact. For example, the National Sleep Foundation (2005) poll estimated that $29 \%$ of adults feel tired at least 3 days a week, and $11 \%$ indicate that their sleepiness seriously impacts their daily activities. Also germane to this issue is the finding that rates of work accidents are 7 times higher in individuals who have insomnia than in good sleepers (Leger, Guilleminault, Bader, Levy, \& Paillard, 2002). Disruptions in sleep patterns are particularly prominent in some clinical groups: Patients with mood disorders, anxiety disorders, schizophrenia, or borderline personality disorder often have serious sleep dysfunctions (for a review, see Benca, Obermeyer, Thisted, \& Gillin, 1992).

A related line of research focuses on the link between dissociative symptoms and sleep. Dissociative symptoms include subjective experiences such as derealization, absorption, and memory complaints. In their mild form, dissociative symptoms are quite common in the general population (Gershuny \& Thayer, 1999), yet they are particularly pronounced in diagnostic groups (e.g., individuals with borderline personality disorder, posttraumatic stress disorder [PTSD], schizophrenia, and the dissociative disorders; Holmes et al., 2005; Merckelbach, à Campo, Hardy, \& Giesbrecht, 2005). There is an impressive amount of literature on the topic of dissociation; however, researchers in this domain have primarily focused on the alleged traumatic etiology of dissociative experiences (for a review, see Kihlstrom, 2005). Although research on the distal antecedents (i.e., dysfunctional family environment) of

Timo Giesbrecht, Department of Experimental Psychology, Maastricht University, Maastricht, the Netherlands, and Department of Psychiatry, Mount Sinai School of Medicine, New York; Tom Smeets, Jimmie Leppink, Marko Jelicic, and Harald Merckelbach, Department of Experimental Psychology, Maastricht University.

Correspondence concerning this article should be addressed to Timo Giesbrecht, Department of Experimental Psychology, Maastricht University, P.O. Box 616, 6200 MD, the Netherlands. E-mail: t.giesbrecht@ psychology.unimaas.nl dissociation has revealed clinically relevant findings, little is known about the more proximal mechanisms involved in dissociation. Of interest, a number of recent studies (Giesbrecht, Jongen, Smulders, \& Merckelbach, 2006; Giesbrecht \& Merckelbach, 2004; Watson, 2001, 2003) have linked dissociative symptoms in undergraduate students to self-reported sleep anomalies, such as flying dreams, hypnopompic imagery, or sensing the presence of someone else. There is also anecdotal evidence that symptoms in patients with depersonalization disorder become worse when they feel tired. Thus, Simeon and Abugel (2006) reported that these patients "often liken it to bad jetlag and feel much worse when they travel across time zones" (p. 210). Similarly, Agargun et al. (2003) emphasized the importance of nightmares in dissociative identity disorder. Taken together, these findings led us to hypothesize that disruptions in the sleep-wake cycle might intensify dissociative symptoms. So far, studies exploring the link between dissociation and sleep pattern disruptions rested entirely on a correlational approach. One inherent limitation of this approach is that it precludes the deduction of causal relations between various variables.

Sleep disturbances can reliably be induced in healthy participants by depriving them of normal sleep. If dissociative experiences are, indeed, fueled by a labile sleep-wake cycle, one would expect sleep loss to increase dissociative symptoms. In the present study, we tested this hypothesis in a sample of healthy undergraduates. We also examined whether sleep loss specifically affects dissociative symptomatology or leads to a more global increase in symptoms. To this end, we measured not only dissociation but also mood fluctuations and the tendency to report hallucinatory experiences.

\section{Method}

\section{Participants}

Participants were 25 healthy undergraduate students ( 15 women and 10 men) enrolled at Maastricht University. Their mean age was 19.56 years $(S D=1.58$; range $=18$ to 23 years $)$. Participants 
received a monetary reward (the equivalent of \$150). All participants were nonsmokers. Further exclusion criteria were any kind of sleeping medication, substance misuse or dependence, serious medical disease, or endocrinological disorder. The study was approved by the standing ethical committee of the Faculty of Psychology of Maastricht University, and all participants gave their written informed consent.

\section{Psychometric Instruments}

Peritraumatic Dissociative Experiences Questionnaire (PDEQ; Marshall, Orlando, Jaycox, Foy, \& Belzberg, 2002). The PDEQ is the most widely used self-report measure of peritraumatic dissociative reactions and consists of eight items. These items quantify the amount of acute dissociation that people experience during a specific event. Respondents are asked to indicate on a 5-point scale $(1=$ not at all true, $5=$ extremely true $)$ to what extent they experienced particular dissociative symptoms (e.g., "I felt confused or couldn't make sense of what was happening"). In the present study, the Dutch translation of the modified version was used. The PDEQ was always administered in combination with the dot-staring task (described later).

Clinician-Administered Dissociative States Scale (CADSS; Bremner et al., 1998). The CADSS is reliable and valid instrument of state symptoms of dissociation. This scale includes 19 self-report and 8 observer-rated items. Severity of each dissociative symptom can range from 0 (not present) to 4 (extremely present). Participants were instructed to use the hour preceding the measurement as their reference point. Because of the design of our study, it was not possible to collect accurate ratings for the 8 observer items. Therefore, only the self-report items were administered (see also Morgan et al., 2001). A sample item is "Do you feel as if you are watching the situation as an observer or spectator?"

Stanford Sleepiness Scale (SSS; Hoddes, Zarcone, Smythe, Phillips, \& Dement, 1973). The SSS is a measure of subjective sleepiness and consists of a 7-point scale with response options ranging from feeling active, vital, alert, and wide awake to almost in reverie, sleep onset soon, and lost in struggle to remain awake. The SSS is widely used in sleep deprivation research (e.g., Babkoff, Caspy, \& Mikulincer, 1991).

Profile of Mood States (POMS; McNair, Lorr, \& Droppleman, 1992). Mood was assessed with the Profile of Mood StatesShort Form. The POMS is a self-report measure that is commonly used to index typical and persistent mood reactions to current life situations. Participants indicate on 5-point scales $(0=$ not at all, 4 = extremely) to what extent they agree with adjectives (e.g., annoyed, nervous, angry) describing their current mood or feelings. The POMS has excellent psychometric properties (see, e.g., Lezak, Howieson, \& Loring, 2004; McNair et al., 1992). The present study used a Dutch version of the POMS that has been proven to be both valid and reliable (de Groot, 1991; Wald \& Mellenberg, 1990). On basis of the POMS scores, we calculated a general distress composite by summing up all Tension-Anxiety, Depression-Dejection, and Anger-Hostility items. Moreover, the POMS Fatigue-Inertia subscale was used as a concurrent measure of sleepiness.

\section{Cognitive Tasks}

Dot-staring task. The dot-staring task has been successfully used by Leonard, Telch, and Harrington (1999) and Miller, Brown, DiNardo, and Barlow (1994) to induce state dissociation in healthy participants. In the present study, participants underwent a 10-min dot-staring task while wearing headphones that dampened all auditory stimulation. This means that all visual and auditory stimulation was minimized temporarily.

White Christmas hallucination (WCH). Participants were instructed that Bing Crosby's famous White Christmas song might be played and that their task was to signal online if they believed they were hearing the song (for an example of this paradigm, see Merckelbach \& van de Ven, 2001). Specifically, participants first entered a room in which Bing Crosby's song was playing. Next, they were told that they were going to hear over headphones a tape with white noise for a 3-min period. They then received the following instructions: "the White Christmas song you just heard might be embedded in the white noise below the auditory threshold. If you think or believe that you hear the song clearly, please press the button in front of you. Of course, you may press the button several times if you think that you heard several fragments of the song." Following this, participants were given the headphones, and the tape with white noise was started. The White Christmas song was never presented during the 3-min period. The frequency with which participants pressed the button was recorded.

\section{Procedure}

Participants arrived at the lab at 9 a.m. and stayed until 4 p.m. the next day. Thus, participants were not sleep deprived at Day 1, and this allowed us to use participants as their own controls. Participants were tested in groups of 5 and had to stay awake and refrain from coffee during the whole study period. Participants were continuously monitored by at least one experimenter to ensure adherence to instructions. They received standardized meals at noon and 5.30 p.m. on Day 1 and at 12:30 a.m., 7 a.m., and noon on Day 2. Participants were allowed to interact with each other but were discouraged from discussing matters pertaining to the study. Participants were allowed to read, watch DVDs, play games, or surf the Internet. They went for a 30-min walk outside at 6 p.m. on Day 1 and 8 a.m. on Day 2. The rationale of the study was not discussed with participants prior to the debriefing. However, participants were told that they had to stay up for the entire night, until the end of the study, and that every $6 \mathrm{hr}$ they were to complete a number of measures.

Sleepiness and dissociative symptoms were assessed every $6 \mathrm{hr}$. Sleepiness was measured with the SSS. Present-state dissociative symptoms were quantified with the CADSS. During each measurement session, the SSS and the CADSS were followed by a dot-staring task intended to induce acute dissociation. Acute dissociative experiences were quantified with the PDEQ, which was administered right after each dot-staring session. Next, participants underwent the $\mathrm{WCH}$. The SSS, the CADSS, the dot-staring task, the PDEQ, and the WCH were administered at 9 a.m., 3 p.m., and 9 p.m. on Day 1 and at 3 a.m., 9 a.m., and 3 p.m. on Day 2. Moreover, at 9 a.m., 3 a.m., and 3 p.m. on Day 2, the POMS was administered prior to the SSS and the CADSS. To avoid carry-over 
effects, we chose not to counterbalance our measures. That is, we wanted to make sure that our measure of spontaneous dissociative symptoms (i.e., the CADSS) was not confounded by dissociative symptoms elicited during the dot-staring task.

\section{Results}

\section{Dissociation and Sleepiness}

Figure 1 shows SSS, PDEQ, and CADSS scores throughout the study. These scores were evaluated with analysis of variance with time as a repeated measure. The Greenhouse-Geisser correction was applied to the probability values associated with multiple degrees of freedom repeated measures. Multiple pairwise comparisons were Bonferroni corrected.

Cronbach's alphas were calculated to assess internal consistencies of the PDEQ, the CADSS, and the POMS at different points in time (see Table 1). Note that low Cronbach's alphas during the first part of our study are related to minimal item variability of the measures (i.e., participants scored consistently low). A case in point is the pattern evident for the CADSS. At the first and second test, respectively, only 6 and 8 of the 19 CADSS items displayed nonzero variance. In contrast, on later tests, all or nearly all CADSS items exhibited variability (see Table 1). This is paralleled by the standard deviations of the CADSS (see Table 2). At Tests 1 and 2, standard deviations were 1.46 and 1.36, respectively. However, at later tests, standard deviations increased considerably, with a standard deviation of 7.95 at the final test, which is a 4.45-fold increase compared with the first test. Other measures followed a similar pattern with substantially higher standard deviations and Cronbach's alphas at later tests relative to earlier tests. We note in passing that at the final tests, Cronbach's alphas are high. Thus, it is certainly not the case that after sleep loss, participants filled out questionnaires more haphazardly because of, for example, poor attention or concentration.

We investigated whether sleepiness, as measured with the SSS, increased over time. This analysis revealed a significant main effect of time, $F(3.62,24)=27.16, p<.01, \eta^{2}=.53$. Pairwise comparisons between adjacent time points indicated that this effect was due to sleepiness increases between 9 p.m. and 3 a.m., $t(24)=$ 2.14, $p<.05$. Using a similar analytic approach for CADSS and PDEQ scores, we tested whether dissociative levels increased as a function of sleep deprivation. Indeed, both CADSS scores, $F(1.58$ $24)=7.86, p<.01, \eta^{2}=.25$, and PDEQ scores, $F(1.59,24)=$ $18.64, p<.01, \eta^{2}=.44$, increased over time. Pairwise comparisons between adjacent time points showed that this increase manifested itself both between 9 p.m. and 3 a.m.-CADSS, $t(24)=3.02, p<.05 ;$ PDEQ, $t(24)=3.66, p<.01$ - and between 3 a.m. and 9 a.m.-CADSS, $t(24)=3.36, p<.05$; PDEQ, $t(24)=$ 4.94, $p<.01$.

Table 3 presents nonparametric zero-order intercorrelations between SSS, CADSS, PDEQ, and WCH scores at the different test sessions. As can be seen, for most sessions after 3 a.m. at Day 2, dissociation levels, as measured by the CADSS or the PDEQ, were significantly related to sleepiness, as measured by the SSS. During these test sessions, CADSS and PDEQ correlated with each other, indicating that they tap related constructs. However, correlations

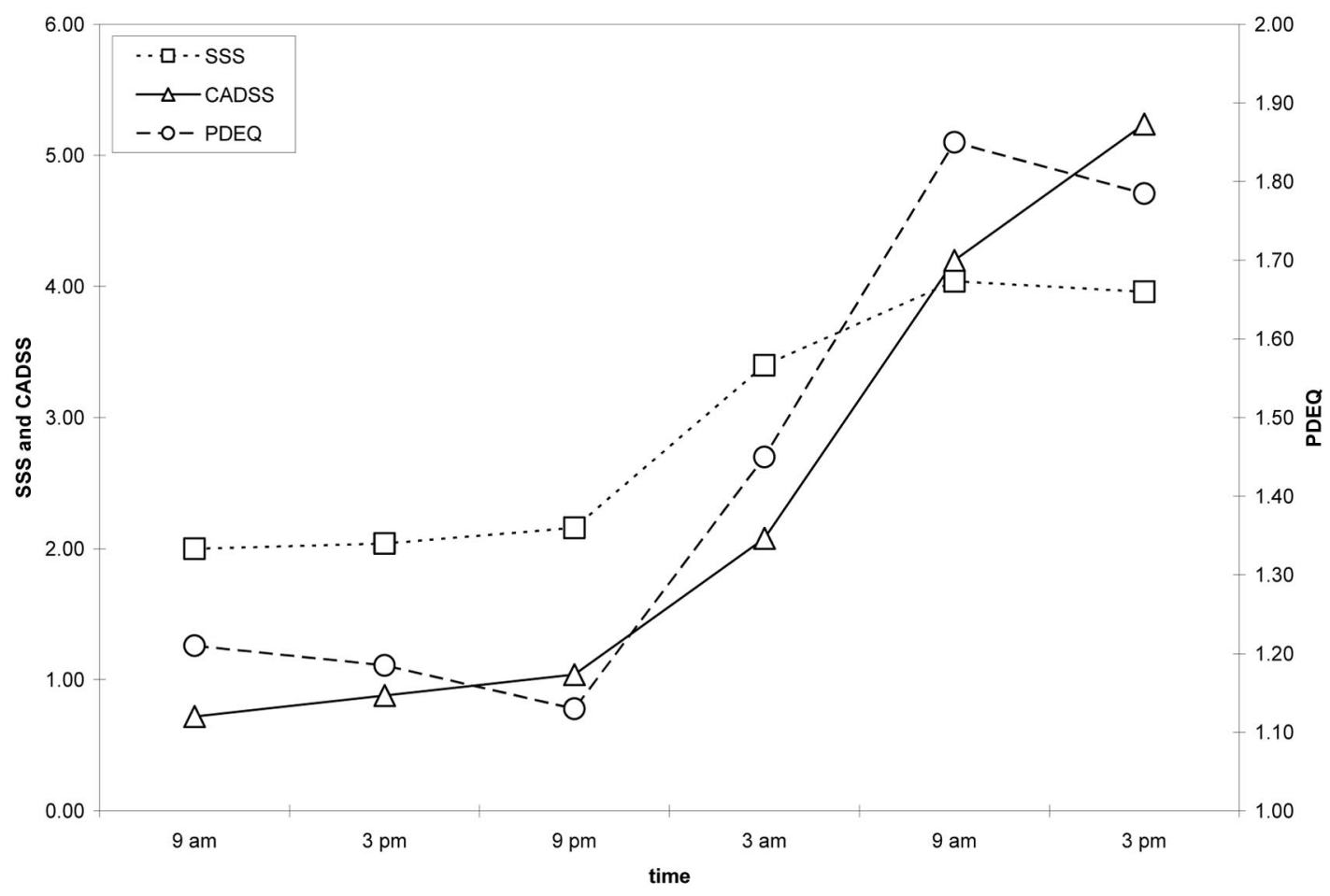

Figure 1. Scores on the Stanford Sleepiness Scale (SSS), the Clinician-Administered Dissociative States Scale (CADSS), and the Peritraumatic Dissociative Experiences Questionnaire (PDEQ) for an undergraduate sample $(N=25)$ at different testing times. 
Table 1

Internal Consistency and Item Variability of Study Measures at Different Tests for an Undergraduate Sample $(N=25)$

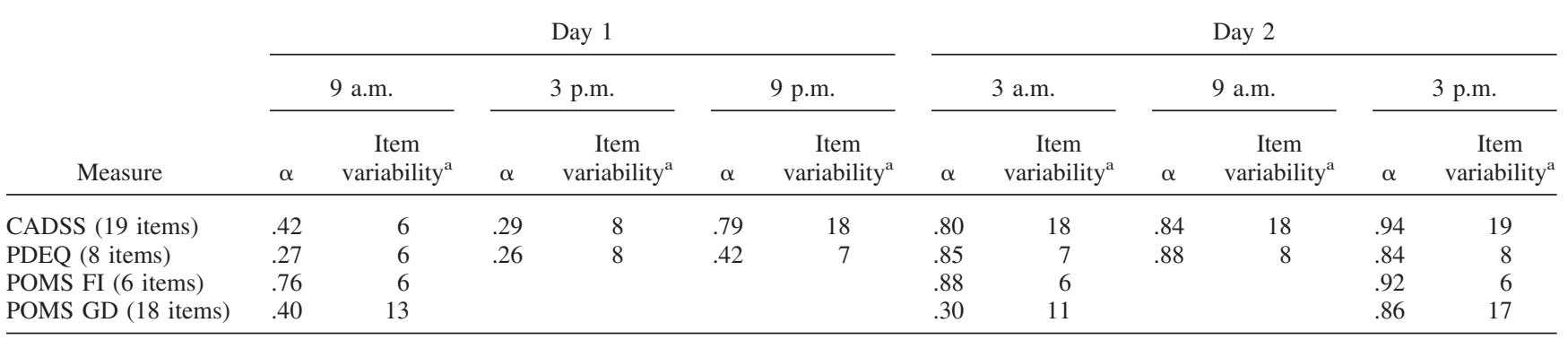

Note. $\quad$ CADSS = Clinician-Administered Dissociative States Scale; PDEQ = Peritraumatic Dissociative Experiences Questionnaire; POMS FI = Profile of Mood States Fatigue-Inertia subscale; POMS GD = Profile of Mood States general distress composite.

${ }^{a}$ Table values for item variability are the number of items for a given test without zero variance.

between the dissociation measures were not consistent, that is, they fell short of significance at Day 1 but were significant at Day 2 . We believe that this has to do with the low variability of some of our measures, especially on Day 1 (see Table 2). To investigate this, we collapsed data across all time points and then again calculated correlations (see the lower part of Table 3). Evidently, this approach greatly increases the range of the measures. Of interest, the resulting correlational pattern is much more straightforward. In line with our Day 2 findings, the CADSS and the PDEQ overlapped considerably, as did our two measures of fatigue (i.e., the SSS and the POMS FI). Moreover, both measures of fatigue were related to dissociation scores with correlations ranging from .51 to .43 .

\section{WCH}

Table 2 presents mean frequencies (and standard deviations) with which participants reported hearing fragments from the White Christmas song. To investigate whether this frequency changed after sleep loss, we conducted a repeated measures analysis of variance with time as the repeated measure. This analysis did not reveal a significant effect of time, $F(2.87,24)=1.53, p>.05$, $\eta^{2}=.06$. Moreover, correlational analyses with data collapsed across all time points showed that WCH scores were weakly related to the CADSS and unrelated to the PDEQ.

\section{POMS}

Table 2 also shows POMS Fatigue-Inertia and general distress composite scores throughout the study. We examined whether fatigue increased over time. As was the case for the SSS index, this yielded a significant main effect of time, $F(1.41,24)=40.91, p<$ $.01, \eta^{2}=.63$. Pairwise comparisons between adjacent time points indicated that this effect was due to Fatigue-Inertia increases both between 9 a.m. and 3 a.m., $t(24)=3.47, p<.01$, and between 3 a.m. and 3 p.m., $t(24)=5.92, p<.01$. Furthermore, we tested whether general distress, as measured by the POMS general distress composite, increased over time. This analysis revealed a significant main effect of time, $F(1.29,24)=8.65, p<.01, \eta^{2}=$ .27. Pairwise comparisons between adjacent time points indicated that this effect was due to distress increases between 3 a.m. and 3 p.m., $t(24)=2.92, p<.01$. Thus, POMS general distress scores increased at a later point in time than dissociation scores.

To further explore the possibility that acute dissociation levels might be mediated (Baron \& Kenny, 1986) by general distress rather than sleepiness per se, we conducted two stepwise regression analyses with CADSS and PDEQ indices of acute dissociation during the final test session (i.e., at maximal sleep loss) as dependent variables. Gender, age, POMS Fatigue-Inertia, and POMS general distress, measured at the same point in time, functioned as predictors. These analyses indicated that the POMS Fatigue-

Table 2

Mean Scores and Standard Deviations of Study Measures for an Undergraduate Sample $(N=25)$ at Different Test Sessions

\begin{tabular}{|c|c|c|c|c|c|c|c|c|c|c|c|c|}
\hline \multirow[b]{3}{*}{ Measure } & \multicolumn{6}{|c|}{ Day 1} & \multicolumn{6}{|c|}{ Day 2} \\
\hline & \multicolumn{2}{|c|}{9 a.m. } & \multicolumn{2}{|c|}{3 p.m. } & \multicolumn{2}{|c|}{9 p.m. } & \multicolumn{2}{|c|}{3 a.m. } & \multicolumn{2}{|c|}{9 a.m. } & \multicolumn{2}{|c|}{3 p.m. } \\
\hline & $M$ & $S D$ & $M$ & $S D$ & $M$ & $S D$ & $M$ & $S D$ & $M$ & $S D$ & $M$ & $S D$ \\
\hline SSS & 2.00 & 0.91 & 2.04 & 0.89 & 2.16 & 0.80 & 3.40 & 0.87 & 4.04 & 1.37 & 3.96 & 1.40 \\
\hline CADSS & 0.72 & 1.46 & 0.88 & 1.36 & 1.04 & 2.24 & 2.08 & 2.97 & 4.20 & 4.60 & 5.24 & 7.95 \\
\hline PDEQ & 1.21 & 0.20 & 1.19 & 0.16 & 1.13 & 0.16 & 1.45 & 0.47 & 1.85 & 0.73 & 1.79 & 0.69 \\
\hline $\mathrm{WCH}$ & 1.12 & 1.56 & 1.28 & 1.95 & 1.12 & 1.56 & 1.16 & 1.52 & 1.24 & 1.79 & 0.60 & 0.96 \\
\hline POMS FI & 2.28 & 2.39 & & & & & 4.56 & 3.83 & & & 11.80 & 6.64 \\
\hline POMS GD & 5.28 & 2.62 & & & & & 5.80 & 2.43 & & & 8.60 & 5.66 \\
\hline
\end{tabular}

Note. $\quad \mathrm{SSS}=$ Stanford Sleepiness Scale CADSS $=$ Clinician-Administered Dissociative States Scale; PDEQ = Peritraumatic Dissociative Experiences Questionnaire; $\mathrm{WCH}=$ White Christmas Hallucination; POMS FI = Profile of Mood States Fatigue-Inertia subscale; POMS GD = Profile of Mood States general distress composite. 
Table 3

Spearman Intercorrelations Between the Study Measures in an Undergraduate Sample $(N=25)$ at Different Points and Collapsed Across All Points In Time

\begin{tabular}{|c|c|c|c|c|c|c|c|c|c|c|c|c|c|}
\hline \multirow[b]{2}{*}{ Measure } & \multicolumn{5}{|c|}{ Day 1,9 a.m. } & \multicolumn{3}{|c|}{ Day 1, 3 p.m. } & \multicolumn{5}{|c|}{ Day 1,9 p.m. } \\
\hline & SSS & CADSS & PDEQ & WCH & POMS FI & SSS & CADSS & PDEQ & SSS & CADSS & PDEQ & WCH & POMS FI \\
\hline \multicolumn{14}{|l|}{ Day 1} \\
\hline SSS & - & & & & & - & & & - & & & & \\
\hline CADSS & 0.19 & - & & & & 0.20 & - & & 0.15 & - & & & \\
\hline PDEQ & -0.12 & -0.12 & - & & & -0.10 & 0.15 & - & 0.13 & 0.33 & - & & \\
\hline WCH & -0.08 & 0.25 & 0.18 & - & & 0.04 & 0.23 & 0.00 & 0.19 & 0.31 & -0.14 & & \\
\hline POMS FI & $0.41^{*}$ & 0.15 & $-0.51^{*}$ & 0.18 & - & - & - & - & - & - & - & & \\
\hline POMS GD & 0.32 & -0.24 & 0.10 & -0.03 & 0.23 & - & - & - & - & - & - & & \\
\hline
\end{tabular}

Day 2, 3 a.m.

Day 2, 9 a.m.

Day 2, 3 p.m.

\begin{tabular}{|c|c|c|c|c|c|c|c|c|c|c|c|c|c|}
\hline \\
\hline \\
\hline \\
\hline & & & & & & & & & & & & & \\
\hline \multicolumn{14}{|l|}{$\begin{array}{l}\text { Day } 2 \\
\text { SSS } \\
\text { CADSS } \\
\text { PDEQ } \\
\text { WCH }\end{array}$} \\
\hline \multirow{2}{*}{$\begin{array}{l}\text { POMS FI } \\
\text { POMS GD }\end{array}$} & 0.30 & $0.49^{*}$ & 0.22 & 0.19 & - & - & - & - & $0.47^{*}$ & $0.56^{*}$ & $0.48^{*}$ & 0.08 & - \\
\hline & -0.26 & -0.28 & -0.15 & -0.25 & -0.07 & - & - & - & $0.44^{*}$ & 0.31 & 0.25 & 0.24 & 0.49 \\
\hline
\end{tabular}

Combined $^{\mathrm{a}}$

\begin{tabular}{|c|c|c|c|c|c|}
\hline \\
\hline \multicolumn{6}{|l|}{$\begin{array}{l}\text { Combined }^{\mathrm{a}} \\
\text { SSS }\end{array}$} \\
\hline CADSS & $0.51^{*}$ & - & & & \\
\hline PDEQ & $0.51^{*}$ & $0.53^{*}$ & - & & \\
\hline $\mathrm{WCH}$ & -0.03 & $0.21^{*}$ & 0.07 & - & \\
\hline POMS FI & $0.61^{*}$ & $0.48^{*}$ & $0.43^{*}$ & 0.07 & - \\
\hline POMS GD & $0.25^{*}$ & 0.05 & $0.24^{*}$ & -0.07 & $0.36^{*}$ \\
\hline
\end{tabular}

Note. $\quad$ SSS $=$ Stanford Sleepiness Scale; CADSS $=$ Clinician-Administered Dissociative States Scale; PDEQ = Peritraumatic Dissociative Experiences Questionnaire; WCH = White Christmas Hallucination; POMS FI = Profile of Mood States Fatigue-Inertia subscale; POMS GD = Profile of Mood States general distress composite.

${ }^{\text {a }}$ Between all measurements across testing.

${ }^{*} p \leq .05$

Inertia subscale accounted for $42 \%$ of the variance in CADSS scores $(B=0.78, \beta=.65), t(24)=4.11, p<.01$, and $20 \%$ of the variance in PDEQ scores $(B=0.05, \beta=.44), t(24)=4.60, p<$ .05 . All other predictors were not significant. Thus, the effect of sleep deprivation on dissociation was not mediated by general distress.

\section{Discussion}

To the best of our knowledge, the present study is the first indicating that sleep loss intensifies dissociative symptoms. This was found to be true for both spontaneous dissociative symptoms as measured by the CADSS and symptoms induced by dot-staring and tapped by the PDEQ. In addition, mood, as indexed by our POMS general distress composite, worsened but exhibited a different temporal pattern than dissociation, whereas auditory hallucinatory experiences induced by the $\mathrm{WCH}$ did not increase after sleep loss.

Since the pioneering study of Orne and Scheibe (1964) on sensory deprivation, it has been known that designs such as the present one are susceptible to demand characteristics. There are good grounds for believing that individuals who score high on dissociation are especially sensitive to such tendencies (Merckelbach \& Jelicic, 2004). However, there are three reasons why our findings cannot be solely accounted for by demand characteristics. To begin with, dissociative symptoms followed a specific temporal pattern. That is, they remained stable during the day (i.e., from 9 a.m. to 9 p.m.) and only increased in the evening and during the night. This is in line with the findings of Babkoff and coworkers (1991), who showed that sleepiness after sleep loss underlies strong circadian oscillations. More specifically, these authors showed that sleepiness increases during the night but then recovers slightly during daytime. In the present study, increases in dissociative symptomatology appeared to follow such circadian oscillations in sleepiness. However, our study relied on only 1 night of sleep deprivation. Future studies investigating sensitivity of dissociative symptoms to circadian oscillations after sleep deprivation should preferably use longer periods of sleep loss.

A second reason why our findings cannot be fully accounted for in terms of demand is that scores on both dissociation measures increased in parallel. Meanwhile, our participants did not fall prey more often to the WCH after sleep loss. If our dissociation findings were entirely driven by demand characteristics, one would expect 
that this would also affect hallucinatory reports on the WCH. One would then expect increasing frequencies of hallucinatory reports over time, but we did not find such a pattern. Moreover, when data were collapsed across all time points, correlations between the $\mathrm{WCH}$ and the CADSS and the PDEQ remained weak at best. Of interest, items tapping hallucination-like experiences are often included in scales measuring hypnotic suggestibility, but studies show that correlations between trait dissociation and hypnotic suggestibility are on the order of only .14 (Kirsch \& Lynn, 1998). Likewise, in our study, correlations across all time points between the WCH and the PDEQ and the CADSS were .21 and .07, respectively.

A third reason why the present results cannot be satisfactorily explained in terms of a demand bias to express negative or unusual experiences is that mood changes did not parallel the increase in dissociative symptoms. In sum, then, there are good empirical reasons to rule out demand characteristics as the principal driving force behind our findings. However, as our study did not include a control condition of participants who simulated being sleep deprived, we cannot definitely rule out the possibility that demand characteristics played some role in shaping the results.

A number of previous studies have noted that eating disorders (Valdiserri \& Kihlstrom, 1995), trauma (Mulder, Beautrais, Joyce, \& Fergusson, 1998), and thought intrusions (Spinhoven \& van der Does, 1999) are linked to dissociation in an indirect way, that is, through the operation of third variables. Thus, one could speculate that sleep loss does not influence dissociative symptomatology directly but rather has a detrimental influence on mood, which in turn might lead to a heightened predisposition to dissociate or simply increase participants' tendency to say eccentric things about themselves. However, our findings do not support this line of reasoning. We found that dissociative symptoms increase prior to mood deteriorations. Furthermore, we found that even after maximum sleep loss, fatigue rather than mood deteriorations predict dissociative tendencies. Unfortunately, we administered mood measures less frequently than dissociation and sleepiness measures, which makes it difficult to compare the precise trajectories of these variables.

Because our participants were healthy undergraduates with homogeneous (i.e., low) initial dissociation levels, our study cannot elucidate whether sleep loss actually triggers dissociation or works as a catalyst, increasing preexisting dissociative tendencies. Therefore, it would be helpful if future sleep-deprivation studies would look at the relationship between traitlike dissociative tendencies and increases in dissociative symptomatology in more diverse and larger samples. Indeed, sample size is important, as one of the problems of the current study is that its limited sample hampers interpretation of nonsignificant correlations at various points in time. It would also be informative if future studies would systematically sample depression and schizotypy. Depression has been shown to be related to insomnia (Tsuno, Besset, \& Ritchie, 2005), and schizotypy is intimately linked to both nightmares (e.g., Watson, 2001) and dissociation (Merckelbach \& Giesbrecht, 2006).

The effect of sleep loss on dissociative symptoms that we found in the present study is likely to be an underestimation, as our participants were healthy undergraduates. This group might be less affected by sleep deprivation than clinical groups. Older individuals require less sleep than younger ones. Therefore, the effect of a single night of sleep deprivation on dissociation might be dif- ferent in various age groups. Nevertheless, the relatively high incidence of sleep dysfunctions (National Sleep Foundation, 2005) highlights the relevance of our findings, particularly because the amount of sleep loss that we induced in the present study is regularly encountered in the general population.

Our findings nicely fit with the notion that disruptions in circadian rhythms affect wakefulness and arousal and have detrimental effects on memory and attentional control (see also Simeon \& Abugel, 2006; Watson, 2001). Thus, sleepiness might contribute to the attentional deficits that are typically found in undergraduates high on dissociation (Giesbrecht, Merckelbach, Geraerts, \& Smeets, 2004) and in patients with dissociative disorders (Guralnik, Schmeidler, \& Simeon, 2000; Simeon \& Abugel, 2006). Germane to this issue are studies showing that dissociation and depersonalization symptoms are related to lowered levels of urinal norepinephrine (Simeon, 2004), a neurotransmitter regulating arousal and alertness. An additional consequence of disruptions in the sleep-wake cycle of individuals high on dissociation might be the intrusion of sleep phenomena (e.g., dreamlike experiences) into waking consciousness, resulting in feelings of depersonalization and derealization (Watson, 2001).

The finding that sleep loss increases acute dissociative symptoms might have implications for groups that are regularly sleep deprived, such as medical interns and long-shift workers. Sleepdeprived people have a higher risk of becoming involved in accidents (e.g., Leger et al., 2002). This accident proneness is commonly ascribed to poor attention and concentration due to sleep loss (Jewett, Dijk, Kronauer, \& Dinges, 1999). However, our findings raise the possibility that in sleep deprived people, acute dissociative symptoms might interfere with conscious cognitive control, which in turn may make these people accident prone. Tentative evidence for this comes from studies showing a robust overlap between traitlike dissociative tendencies and scores on the Cognitive Failures Questionnaire (CFQ; Merckelbach, Horselenberg, \& Schmidt, 2002; Merckelbach, Muris, \& Rassin, 1999). The CFQ measures the frequency of everyday cognitive failures, such as forgetting names, missing signs on the road, or being distracted. Individuals who score high on the CFQ are also more likely to become involved in accidents (Wallace \& Vodanovich, 2003). Clearly, the links between sleep loss, acute dissociative symptoms, and accident proneness merit further research.

The present findings may also be helpful in understanding why there is such a robust connection between dissociation and memory commission errors. A typical feature of the cognitive architecture of people high on dissociation is that they tend to produce pseudomemories (i.e., false alarms, commission errors) on memory tasks (Candel, Merckelbach, \& Kuijpers, 2003; Giesbrecht, Geraerts, \& Merckelbach, 2007; Merckelbach, Zeles, van Bergen, \& Giesbrecht, 2007). Thus, it may well be that the dreamlike intrusions into waking state that are typical of dissociation interfere with memory performance in such a way that commission errors occur. The present study did not include any memory measures, yet we do think that the link between dissociation, memory commission errors, and sleep loss warrants further study.

In sum, although the present study is a long way from offering direct therapeutically relevant insights, it does highlight the relevance of (disruptions in) sleep patterns to dissociative symptoms and dissociative disorders. Our findings require replication in clinically relevant groups, and if such replications are successful, 
the question would arise of whether patients with dissociation may profit from therapeutic approaches directed at normalizing sleep patterns and reducing nightmares. Taken together, the present and earlier findings (Giesbrecht et al., 2006; Giesbrecht \& Merckelbach, 2004, 2006; Watson, 2001) suggest that the study of how sleep patterns relate to dissociative symptoms is a fruitful research area that might eventually lead to new therapeutic approaches in the treatment of the dissociative disorders and other conditions that are characterized by heightened levels of dissociation (e.g., PTSD).

\section{References}

Agargun, M. Y., Kara, H., Ozer, O. A., Selvi, Y., Kiran, U., \& Ozer, B. (2003). Clinical importance of nightmare disorder in patients with dissociative disorders. European Archives of Psychiatry and Clinical Neurosciences, 57, 575-579.

Babkoff, H., Caspy, T., \& Mikulincer, M. (1991). Subjective sleepiness ratings: The effects of sleep deprivation, circadian rhythmicity and cognitive performance. Sleep, 14, 534-539.

Baron, R. M., \& Kenny, D. A. (1986). The moderator-mediator variable distinction in social psychological research: Conceptual, strategic, and statistical considerations. Journal of Personality and Social Psychology, $51,1173-1182$

Benca, R. M., Obermeyer, W. H., Thisted, R. A., \& Gillin, J. C. (1992). Sleep and psychiatric disorders: A meta-analysis. Archives of General Psychiatry, 49, 651-668.

Bremner, J. D., Krystal, J. H., Putnam, F. W., Southwick, S. M., Marmar, C., Charney, D. S., et al. (1998). Measurement of dissociative states with the Clinician-Administered Dissociative States Scale (CADSS). Journal of Traumatic Stress, 11, 125-136.

Candel, I., Merckelbach, H., \& Kuijpers, M. (2003). Dissociative experiences are related to commissions in emotional memory. Behaviour Research and Therapy, 41, 719-725.

de Groot, M. H. (1991). Psychometrische aspecten van een stemmingsschaal (Verkorte POMS) [Psychometric properties of a mood scale (POMS short version)]. Gedrag en Gezondheid, 20, 46-51.

Gershuny, B. S., \& Thayer, J. F. (1999). Relations among psychological trauma, dissociative phenomena, and trauma-related distress: A review and integration. Clinical Psychology Review, 19, 631-637.

Giesbrecht, T., Geraerts, E., \& Merckelbach, H. (2007). Dissociation, memory commission errors, and heightened autonomic reactivity. Psychiatry Research, 150, 277-285.

Giesbrecht, T., Jongen, E., Smulders, F., \& Merckelbach, H. (2006). Dissociation, cortical activity, and sleep. Journal of Nervous and Mental Disease, 194, 362-368.

Giesbrecht, T., \& Merckelbach, H. (2004). Subjective sleep experiences are related to dissociation. Personality and Individual Differences, 37, $1341-1345$.

Giesbrecht, T., \& Merckelbach, H. (2006). Dreaming to reduce fantasyFantasy proneness, dissociation and subjective sleep experiences. Personality and Individual Differences, 41, 697-706.

Giesbrecht, T., Merckelbach, H., Geraerts, E., \& Smeets, E. (2004). Disruptions in executive functioning and dissociation in undergraduate students. Journal of Nervous and Mental Disease, 192, 567-569.

Guralnik, O., Schmeidler, J., \& Simeon, D. (2000). Feeling unreal: Cognitive processes in depersonalization. American Journal of Psychiatry, 157, 103-109.

Hoddes, E., Zarcone, V., Smythe, H., Phillips, R., \& Dement, W. C. (1973). Quantification of sleepiness: A new approach. Psychophysiology, 10, 431-436.

Holmes, E. A., Brown, R. J., Mansell, W., Fearon, R., Hunter, E. C. M., Frasquilho, F., et al. (2005). Are there two qualitatively distinct forms of dissociation? A review and some clinical implications. Clinical Psychology Review, 25, 1-23.

Jewett, M. E., Dijk, D.-J., Kronauer, R. E., \& Dinges, D. F. (1999). Dose-response relationship between sleep duration and human psychomotor vigilance and subjective alertness. Sleep, 22, 171-179.

Kihlstrom, J. F. (2005). Dissociative disorders. Annual Review of Clinical Psychology, 1, 1-27.

Kirsch, I., \& Lynn, S. J. (1998). Dissociation theories of hypnosis. Psychological Bulletin, 123, 100-115.

Leger, D., Guilleminault, C., Bader, G., Levy, E., \& Paillard, M. (2002). Medical and socio-professional impact of insomnia. Sleep, 25, 625-629.

Leonard, K. N., Telch, M. J., \& Harrington, P. J. (1999). Dissociation in the laboratory: A comparison of strategies. Behaviour Research and Therapy, 37, 49-61.

Lezak, M. D., Howieson, D. B., \& Loring, D. W. (2004). Neuropsychological assessment. Oxford, England: Oxford University Press.

Marshall, G. N., Orlando, M., Jaycox, L. H., Foy, D. W., \& Belzberg, H. (2002). Development and validation of a modified version of the Peritraumatic Dissociative Experiences Questionnaire. Psychological Assessment, 14, 123-134.

McNair, D. M., Lorr, M., \& Droppleman, L. F. (1992). The Profile of Mood States (POMS) manual. San Diego, CA: EdITS

Merckelbach, H., à Campo, J., Hardy, S., \& Giesbrecht, T. (2005). Dissociation and fantasy proneness in psychiatric patients: A preliminary study. Comprehensive Psychiatry, 16, 181-185.

Merckelbach, H., \& Giesbrecht, T. (2006). Subclinical dissociation, schizotypy, and traumatic distress. Personality and Individual Differences, 40, 365-374.

Merckelbach, H., Horselenberg, R., \& Schmidt, H. (2002). Modeling the connection between self-reported trauma and dissociation in a student sample. Personality and Individual Differences, 32, 695-705.

Merckelbach, H., \& Jelicic, M. (2004). Dissociative symptoms are related to endorsement of vague trauma items. Comprehensive Psychiatry, 45 , $70-75$.

Merckelbach, H., Muris, P., \& Rassin, E. (1999). Fantasy proneness and cognitive failures as correlates of dissociative experiences. Personality and Individual Differences, 26, 961-967.

Merckelbach, H., \& van de Ven, V. (2001). Another White Christmas: Fantasy proneness and reports of "hallucinatory experiences" in undergraduate students. Journal of Behavior Therapy and Experimental Psychiatry, 32, 137-144.

Merckelbach, H., Zeles, G., van Bergen, S., \& Giesbrecht, T. (2007). Trait dissociation and commission errors in memory reports of emotional events. American Journal of Psychology, 120, 1-14.

Miller, P. P., Brown, T. A., DiNardo, P. A., \& Barlow, D. H. (1994). The experimental induction of depersonalization and derealization in panic disorder and nonanxious subjects. Behaviour Research and Therapy, 32, 511-519.

Morgan, C. A., III, Hazlett, G., Wang, S., Richardson, E. G., Jr., Schnurr, P., \& Southwick, S. M. (2001). Symptoms of dissociation in humans experiencing acute, uncontrollable stress: A prospective investigation. American Journal of Psychiatry, 158, 1239-1247.

Mulder, R. T., Beautrais, A. L., Joyce, P. R., \& Fergusson, D. M. (1998). Relationship between dissociation, childhood sexual abuse, and mental illness in a general population sample. American Journal of Psychiatry, $155,806-811$.

National Sleep Foundation. (2005). Sleep in America poll. Washington, DC: Author.

Orne, M. T., \& Scheibe, K. E. (1964). The contribution of nondeprivation factors in the production of sensory deprivation effects: The psychology of the "panic button." Journal of Abnormal and Social Psychology, 68, $3-12$.

Simeon, D. (2004). Depersonalisation disorder: A contemporary overview. CNS Drugs, 18, 343-354. 
Simeon, D., \& Abugel, J. (2006). Feeling unreal: Depersonalization disorder and the loss of the self. New York: Oxford University Press.

Spinhoven, P., \& van der Does, A. J. W. (1999). Thought suppression, dissociation and psychopathology. Personality and Individual Differences, 27, 877-886.

Tsuno, N., Besset, A., \& Ritchie, K. (2005). Sleep and depression. Journal of Clinical Psychiatry, 66, 1254-1269.

Valdiserri, S., \& Kihlstrom, J. F. (1995). Abnormal eating and dissociative experiences: A further study of college women. International Journal of Eating Disorders, 18, 145-150.

Wald, F. D. M., \& Mellenberg, G. J. (1990). De verkorte versie van de Nederlandse vertaling van de Profile of Mood States (POMS). [The brief version of the Dutch translation of the Profile of Mood States (POMS)]. Nederlands Tijdschrift Voor de Psychologie, 45, 86-90.
Wallace, J. C., \& Vodanovich, S. J. (2003). Can accidents and industrial mishaps be predicted? Further investigation into the relationship between cognitive failure and reports of accidents. Journal of Business and Psychology, 17, 503-514.

Watson, D. (2001). Dissociations of the night: Individual differences in sleep-related experiences and their relation to dissociation and schizotypy. Journal of Abnormal Psychology, 110, 526-535.

Watson, D. (2003). To dream, perchance to remember: Individual differences in dream recall. Personality and Individual Differences, 34, 12711286.

Received June 13, 2006

Revision received January 25, 2007

Accepted January 29, 2007

\section{Low Publication Prices for APA Members and Affiliates}

Keeping you up-to-date. All APA Fellows, Members, Associates, and Student Affiliates receive-as part of their annual dues-subscriptions to the American Psychologist and APA Monitor. High School Teacher and International Affiliates receive subscriptions to the APA Monitor, and they may subscribe to the American Psychologist at a significantly reduced rate. In addition, all Members and Student Affiliates are eligible for savings of up to $60 \%$ (plus a journal credit) on all other APA journals, as well as significant discounts on subscriptions from cooperating societies and publishers (e.g., the American Association for Counseling and Development, Academic Press, and Human Sciences Press).

Essential resources. APA members and affiliates receive special rates for purchases of APA books, including the Publication Manual of the American Psychological Association, and on dozens of new topical books each year.

Other benefits of membership. Membership in APA also provides eligibility for competitive insurance plans, continuing education programs, reduced APA convention fees, and specialty divisions.

More information. Write to American Psychological Association, Membership Services, 750 First Street, NE, Washington, DC 20002-4242. 